\section{Dynamic changes in histone H3 Lys 9 methylation occurring at tightly regulated inducible inflammatory genes}

\author{
Simona Saccani and Gioacchino Natoli ${ }^{1}$ \\ Institute for Research in Biomedicine, Via Vela 6, CH6501, \\ Bellinzona, Switzerland
}

\begin{abstract}
Methylation of histone $\mathrm{H} 3$ at Lys 9 is causally linked to formation of heterochromatin and to long-term transcriptional repression. We report an unexpected pattern of H3 Lys 9 methylation occurring at a subset of inducible inflammatory genes. This pattern is characterized by relatively low constitutive levels of H3 Lys 9 methylation that are erased upon activation and restored concurrently with post-induction transcriptional repression. Changes in H3 Lys 9 methylation strongly correlate with RNA polymerase II recruitment and release. In particular, remethylation correlates with RNApolII release more strongly than does histone deacetylation. We propose that, by generating a window of time in which transcription is permitted, dynamic modulation of H3 Lys 9 methylation adds an additional regulatory level to transcriptional activation of tightly controlled inducible genes.
\end{abstract}

Received April 4, 2002; revised version accepted July 9, 2002.

The N-terminal tails of core histones are the convergent substrates of several enzymes controlling transcription and replication (Berger 2001). Combination of several covalent modifications along a single histone tail is believed to generate a sort of encrypted code (histone code; Strahl and Allis 2000), which acts by providing alternative docking surfaces for proteins regulating chromatin organization, transcription, DNA replication and repair (Jenuwein and Allis 2001).

The N-terminal tails of histone $\mathrm{H} 3$ and $\mathrm{H} 4$ are methylated at several lysine and arginine residues, methylation of individual residues being causally linked to either transcriptional activation or repression (Jenuwein 2001; Zhang and Reinberg 2001). Recently, SET-domaincontaining proteins of the evolutionary conserved SU(VAR)3-9 family have been shown to act as lysinespecific histone methyltransferases (HMTases; Rea et al. 2000; Jenuwein 2001). By selectively methylating H3Lys9, SU(VAR)3-9 family HMTases generate a docking site for heterochromatin-associated HP1 proteins (Bannister et al. 2001; Lachner et al. 2001; Nakayama et al. 2001), thus linking H3 Lys 9 methylation to formation and spreading of heterochromatin. Analysis of H3 Lys 9

[Key Words: histone methylation; transcriptional repression; histone methyltransferase; histone code]

${ }^{1}$ Corresponding author.

E-MAIL gioacchino.natoli@irb.unisi.ch; FAX 41-91-820-0305.

Article and publication are at http://www.genesdev.org/cgi/doi/10.1101/ gad.232502. methylation over large chromosomal regions has shown that this modification is preferentially associated with constitutively condensed heterochromatin and with developmentally inactive genes (Litt et al. 2001; Noma et al. 2001). Mammalian Suv39h HMTases are specifically required for the induction of a specialized high-density H3 Lys 9 methylation pattern at pericentric heterochromatin, which is required to protect genome stability in both somatic and germ cells (Peters et al. 2001). Suv39hindependent H3 Lys 9 methylation is directly involved in the chromosome-wide chromatin remodelling leading to the transcriptional shutdown of the inactive $\mathrm{X}$ chromosome (Heard et al. 2001; Boggs et al. 2002; Peters et al. 2002).

Experimental evidence indicates that H3 Lys 9 methylation may also have a wide role in transcriptional repression of euchromatic genes. First, the retinoblastoma tumor suppressor protein recruits SUV39H1 to cell cycle genes, where it mediates H3 Lys 9 methylation and transcriptional repression (Nielsen et al. 2001). Second, a broad euchromatic and heterochromatic Suv39h-independent H3 Lys 9 methylation is observed in mammalian cells (Peters et al. 2001), consistent with the existence of several other potential SET-domain HMTases, some of which methylate $\mathrm{H} 3$ Lys 9 selectively in euchromatin (Ogawa et al. 2002; Schultz et al. 2002). Third, HP1 proteins bind to several euchromatic sites in Drosophila and mammalian cells (James et al. 1989; Minc et al. 2000) and interact with transcriptional corepressors (Lehming et al. 1998; Seeler et al. 1998; Nielsen et al. 1999; Ryan et al. 1999). An attractive model is that some transcriptional corepressors may act as scaffolds recruiting H3 Lys 9 HMTases and HP1 proteins to specific euchromatic sites, thus locally repressing transcription (Schultz et al. 2002). Finally, Drosophila HP1 has been demonstrated to repress selected euchromatic genes in a Su(var)3-9-dependent manner (Hwang et al. 2001).

Regarded as a stable and potentially irreversible modification (Jenuwein and Allis 2001; Zhang and Reinberg 2001), histone methylation at lysine residues is usually considered incompatible with the requirements of rapidly inducible gene expression. Recently, however, it has been reported that H3-Lys 4 methylation at a tandem array of mouse mammary tumor virus (MMTV) promoters is rapidly downregulated upon glucocorticoid hormone treatment ( $\mathrm{Ma}$ et al. 2001). Although the significance of this finding is not clear, it suggests either that the methyl mark can be rapidly removed from histone proteins or that methylated histones can be replaced or degraded.

We therefore set out to analyze H3 Lys 9 methylation at inducible endogenous genes. Evidence from gene-targeted mice and cells lacking transcriptional repressors expressed in cells of the monocytic lineage (Toney et al. 2000; Karsunky et al. 2002) indicates that transcriptional inactivity of some inflammatory genes in unstimulated cells, as well as post-induction transcriptional shutdown, depends on the activity of specific transcriptional repressors. The possibility therefore exists that H3 Lys 9 methylation may mediate repression in this context. We found that in unstimulated cells some inducible genes are associated with nucleosomes methylated at H3 Lys 9 , and that this modification is rapidly reversed upon activation and then restored. 


\section{Results and Discussion}

\section{LPS-induced gene activity in DCs}

Primary human monocyte-derived dendritic cells (DCs; Sallusto and Lanzavecchia 1994) are post-mitotic, terminally differentiated cells that respond to bacterial products and inflammatory cytokines by activating transcription of several genes implicated in inflammation, chemotaxis, and $\mathrm{T}$ lymphocyte activation. The genes we examined are strongly induced by lipopolysaccharide (LPS) stimulation of DCs. A representative set of a larger panel of genes investigated is shown in Figure 1a. Interleukin 8 (IL-8), macrophage inflammatory protein $1 \alpha$ $(\mathrm{MIP}-1 \alpha)$, and $\mathrm{IkB} \alpha$ (inhibitor of nuclear factor $\kappa \mathrm{B}$ ) are induced by inflammatory stimuli in various cell types; low basal $\mathrm{IkB} \alpha$ mRNA levels are detected ubiquitously. Conversely, the genes encoding the macrophage-derived chemokine (MDC), the EBV-induced molecule 1 ligand chemokine (ELC) and the p40 subunit of interleukin 12 (IL-12p40) are expressed exclusively by cells of the monocytic lineage, with DCs being the most efficient producers.

Chromatin immunoprecipitation (ChIP) assays carried
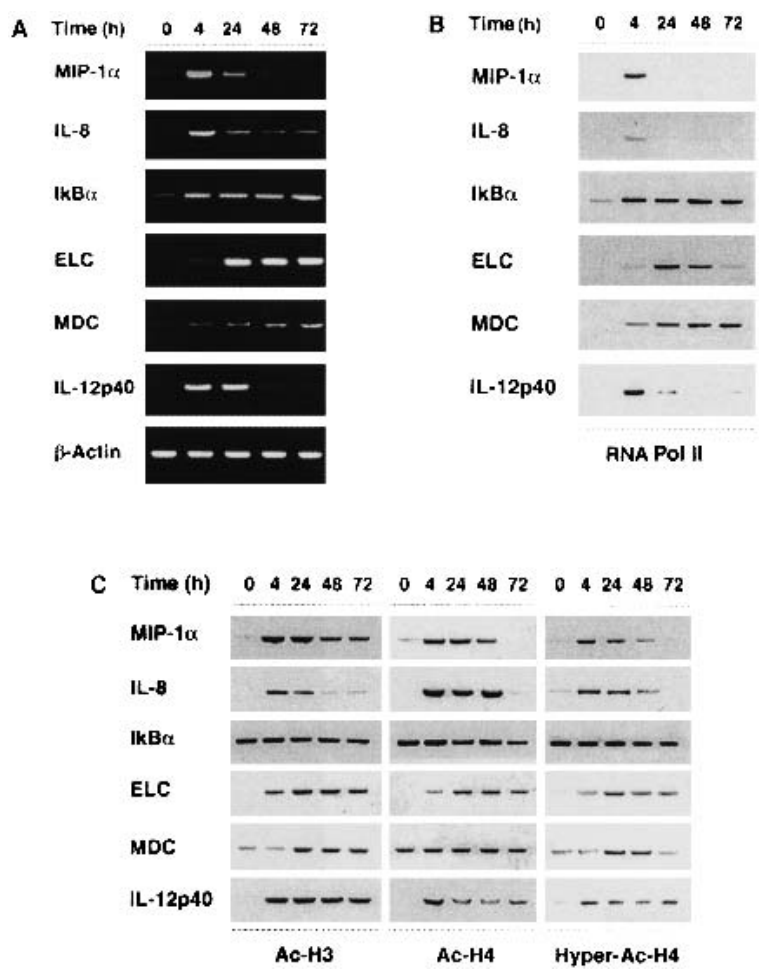

Figure 1. Kinetics of LPS-induced gene expression in human monocyte-derived DCs. (A) Steady-state mRNA levels of LPS-induced genes were analyzed by RT-PCR. Dendritic cells were stimulated with $100 \mathrm{ng} / \mathrm{ml}$ LPS as indicated. $(B)$ RNApolII recruitment to the same genes was analyzed by Chromatin Immunoprecipitation (ChIP) assay using an antibody directed against the RNApolII large subunit Rpb1. Immunoprecipitated DNA was analyzed by PCR using promoter-specific primers. The peak of RNApolII recruitment to the $I k B \alpha, I L-8$ and $M I P-1 \alpha$ genes occurs at earlier time points $(0.5-2$ h) than those shown in the figure. $(C)$ Promoter-specific histone H3 and $\mathrm{H} 4$ acetylation was investigated by ChIP assays carried out with antibodies against acetylated H3 (Ac-Lys 9/Lys 14) and H4. The antibody against hyperacetylated $\mathrm{H} 4$ has a preference towards tetraand tri-acetylated $\mathrm{H} 4$. out with an antibody recognizing the RNA polymerase II (RNApolII) large subunit Rpb1 showed transient recruitment to all genes except $I k B \alpha$, where recruitment was persistent (Fig. 1b). Indeed, $I k B \alpha$ is directly regulated by NF-kB, which undergoes irreversible activation in LPSstimulated DCs. Release of RNApolII from the $M D C$ gene usually started between 48 and $72 \mathrm{~h}$, with different kinetics in DCs from different donors (in this donor a slow kinetics of release was observed). With the exception of $I k B \alpha$, which showed high constitutive levels of histone $\mathrm{H} 3$ and $\mathrm{H} 4$ acetylation (which were left substantially unaffected by stimulation), all of the genes tested underwent hyperacetylation at histone $\mathrm{H} 3$ and $\mathrm{H} 4$ upon LPS stimulation (Fig. 1c). The increase in $\mathrm{H} 3$ and $\mathrm{H} 4$ acetylation levels correlated with recruitment of RNApolII. Remarkably, however, both H3 and H4 hyperacetylation at all the genes tested persisted after RNApolII release. This observation cannot be accounted for by a different sensitivity of anti-polII ChIP versus anti-acetyl H4/H3 ChIPs, as their efficiency is comparable. Thus $\mathrm{H} 3$ and $\mathrm{H} 4$ acetylation levels are not predictive of transcriptional termination at any of the genes analyzed, and RNApolII release occurs independently of any extensive $\mathrm{H} 3 / \mathrm{H} 4$ deacetylation.

\section{Dynamic H3 Lys 9 methylation at inducible inflammatory genes}

To analyze H3 Lys 9 methylation status at the genes under investigation, we used an antibody that specifically recognizes histone $\mathrm{H} 3$ only when methylated at Lys 9. Total H3 Lys 9 methylation (which mainly reflects heterochromatic H3 Lys 9 methylation) did not vary during LPS treatment (Fig. 2a). Using ChIP, we did not detect any H3 Lys 9 methylation above background levels at the $I L-8$ and $I k B \alpha$ promoters (Fig. 2b); a lowlevel H3 Lys 9 methylation was detected in several donors at the $M I P-1 \alpha$ promoter, but only transiently and at late time points, long after transcriptional termination. The significance of this weak, late, and transient H3 Lys 9 methylation is unclear. In contrast to the genes mentioned above, ELC, MDC, and $I L-12 p 40$ promoters were found to be associated with detectable levels of H3 Lys 9 methylation in unstimulated cells. LPS stimulation determined the erasure of H3 Lys 9 methylation at all three promoters, which was followed by remethylation at later time points. Monocytes, which express very low levels of IL-12p40, ELC, and MDC mRNAs, showed similar basal levels of H3 Lys 9 methylation. However, no histone demethylation was observed following LPS treatment (Fig. 2c). Thus H3 Lys 9 demethylation strongly correlates with the high level transcriptional activity specifically observed in DCs.

We next compared the relative density of H3 Lys 9 methylation at the ELC, $M D C$, and $I L-12 p 40$ promoters with the density of $\mathrm{H} 3$ Lys 9 methylation at the promoters of genes known to be assembled into heterochromatin. To this aim, we analyzed H3 Lys 9 methylation at the Xist gene, which is silenced on the active $\mathrm{X}$ chromosome in females and on the single $X$ chromosome in males. By comparing the ChIP signals with serial twofold dilutions of a fraction of the input (and considering a bi-allelic methylation at inflammatory genes versus a mono-allelic methylation at the Xist gene), we estimated H3 Lys 9 methylation at inflammatory genes to be about eight-fold lower than that of Xist (Fig. 2d). However, 
A

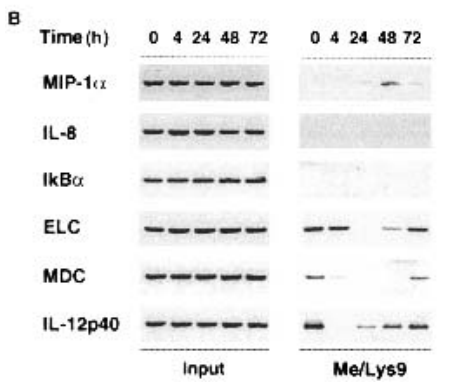

c

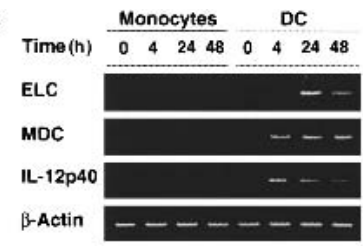

D

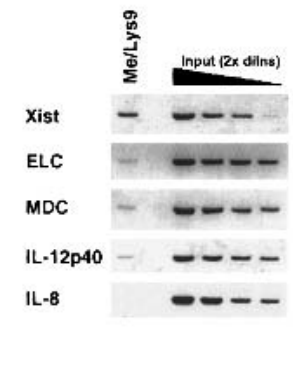

Figure 2. Dynamic changes in histone H3 Lys 9 methylation levels at the promoters of tightly regulated inducible genes. (A) DCs were stimulated with LPS as indicated and bulk levels of H3 methylated at Lys 9 were analyzed by Western blot. $(B)$ Lys 9 methylation of $\mathrm{H} 3$ at the promoters of the genes under investigation was analyzed by ChIP assay. The left panel (Input) shows the relative amounts of the probed regions contained in the starting chromatin extracts. The right panel shows ChIP analysis of specific association of $\mathrm{H} 3$ methylated at Lys 9 with the promoters investigated. The induction of the genes we analyzed is asynchronous in LPS-stimulated DCs. It is therefore possible that the apparent gradation in H3 Lys 9 methylation changes (and in RNApolII recruitment) reflects different kinetics with which such changes occur in individual cells of the population analyzed. $(C)$ LPS-stimulated monocytes express very low levels of ELC, MDC, and IL-12p40 mRNAs (transcripts can be detected at a higher number of PCR cycles). No detectable H3 Lys 9 demethylation was observed in these cells (right). (D) Density of H3 Lys 9 methylation at inducible euchromatic genes with respect to heterochromatic genes. Signals obtained in the Me/Lys 9 ChIP assay were compared to serial twofold dilutions of a fraction of the input. PCR was carried out at a lower number of cycles than in the experiment shown in $B, C$ to maintain the signals obtained with differentially methylated promoters in a linear range. (E) ChIP analysis of promoter-specific H3 Lys 4 methylation at inducible genes. Promoter-specific levels of H3 Lys 4 methylation were analyzed by ChIP assay using an antibody recognizing $\mathrm{H} 3$ methylated at Lys 4 . The negative controls for these experiments were parallel samples in which the immunoprecipitation step was carried out without antibody (data not shown). In these samples, only background levels of promoter sequences were detectable after 40 cycles of PCR.

these data should be interpreted very cautiously: since the anti-methyl H3 Lys 9 antibody has a rather low affinity towards its ligand, a difference in the density of this modification on a string of nucleosomes may have dramatic and non-linear effects on the efficiency of the immunoprecipitation. Therefore, the only conclusion we can draw from these data is that the density of this modification at euchromatic genes is lower than at heterochromatic genes. Precise quantification will have to await the generation of high affinity monoclonal antibodies. The relatively low density of H3 Lys 9 methylation at euchromatic genes may arise either from the selective modification of specific nucleosomes or from hemi-methylation of several nucleosomes. The first situation would be reminiscent of the nucleosome-selective H3 Lys 9 methylation in the cyclin E promoter (Nielsen et al. 2001).

These results indicate that $\mathrm{H} 3$ Lys 9 methylation is a dynamically regulated histone modification targeting specific nucleosomes in a subset of inducible genes. The behavior of the methyl mark at H3 Lys 9 is fully consistent with its known role as a repressive modification. In fact, comparison of RNApolII recruitment kinetics (Fig. 1b) with H3 Lys 9 methylation status (Fig. 2b) indicates that (1) RNApolII recruitment starts when demethylation begins; (2) the peak of RNApolII recruitment to

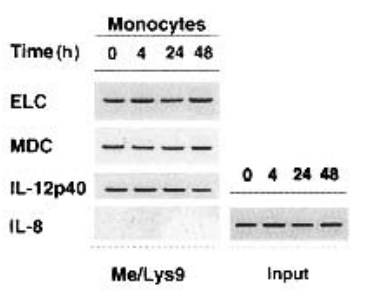

E

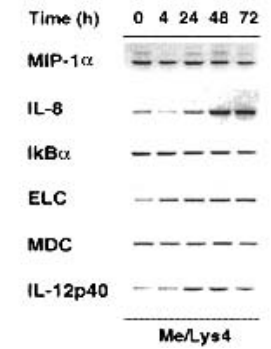

these genes occurs when $\mathrm{H} 3$ Lys 9 methylation is at its lowest level; and (3) release of RNApolII temporally correlates with remethylation. $M D C$ has the slowest remethylation kinetics among the genes tested and, in DCs from several donors, remethylation at $72 \mathrm{~h}$ temporarily overlaps with RNApolII occupancy. The time interval between H3 Lys 9 remethylation and RNApolII release at the $M D C$ gene suggests that remethylation may only pose the gene for repression but is by itself not sufficient.

Overall, changes in H3 Lys 9 methylation status correlated with RNApolII persistence on genes bearing constitutive H3 Lys 9 methylation more than changes in $\mathrm{H} 3 / \mathrm{H} 4$ acetylation status. In particular, H3 Lys 9 remethylation temporally correlated with RNApolII release, while histone deacetylation lagged behind it.

These results suggest that $\mathrm{H} 3$ Lys 9 demethylation and subsequent remethylation may generate a time window that is permissive for transcriptional activation.

\section{H3 Lys 4 methylation \\ at inducible genes}

We next investigated whether inducible gene expression in this system is associated with changes in H3 Lys 4 methylation. Methylation of histone $\mathrm{H} 3$ at Lys 4 correlates with transcriptional activity in tetrahymena (Strahl et al. 1999), Saccharomyce pombe (Noma et al. 2001), and mammals (Heard et al. 2001; Litt et al. 2001; Boggs et al. 2002; Nishioka et al. 2002), while it mediates transcriptional repression in Saccharomyces cerevisiae (Briggs et al. 2001; Nagy et al. 2002). High levels of H3 Lys 4 methylation in S. pombe and mammalian cells are found at transcriptionally active euchromatic regions, thus suggesting that this may act as a stable and long-range mark of active chromatin; indeed, when considering large chromosomal regions, this modification strongly anti-correlates with H3 Lys 9 methylation (Heard et al. 2001; Litt et al. 2001; Boggs et al. 2002). Moreover, enforced expression of an H3 Lys 4-specific HMTase potentiates the activation function of a transcriptional activator (Nishioka et al. 2002). However, the behavior of $\mathrm{H} 3$ Lys 4 methylation at rapidly inducible genes is poorly defined. An antibody directed against methyl H3 Lys 4 (Briggs et al. 2001; Litt et al. 2001; Noma et al. 2001) immunoprecipitated detectable amounts of all the promoters under investigation (Fig. 2e). Control ChIPs carried out with no antibody immunoprecipitated only background amounts of the same promoters (data not shown). At the ELC, $M D C$, and $I L-12 p 40$ genes, H3 Lys 4 methylation therefore coexisted with the constitutive H3 Lys 9 methylation. Since the fragments analyzed have an average size of $1 \mathrm{~kb}$ and 
presumably contain several nucleosomes, it is possible that methylation of the two residues does not coexist on a single H3 molecule, as suggested by in vitro results (Wang et al. 2001; Nishioka et al. 2002). LPS stimulation did not determine dramatic changes in the amount of $\mathrm{H} 3$ methylated at Lys 4 that was associated with these genes, and the changes detected did not follow simple patterns. In detail, Lys 4 methylation at $M I P-1 \alpha, I k B \alpha$, and $M D C$ was substantially stable throughout the treatment. H3 Lys 4 methylation at the $I L-8$ promoter was stable during the first $24 \mathrm{hr}$ of treatment (i.e., the time during which the gene is activated and then again reset to a basal level of activity) and increased at $48 \mathrm{hr}$ (the possible role of this late increase is therefore difficult to understand, as it did not correlate with any change in transcriptional activity). In DCs from several donors (such as the one shown in Fig. 2e), the $I L-12 p 40$ promoter showed a mild increase in Lys 4 methylation (usually lagging behind Lys 9 demethylation), while in DCs from other donors, flat levels of H3 Lys 4 methylation were observed in spite of a strong transcriptional activation (data not shown), thus arguing against a necessary role for increased Lys 4 methylation in transcriptional induction of this gene. ELC was the only gene where we always detected a reproducible increase in H3 Lys 4 methylation, which correlated with RNApolII recruitment. LPS-induced increase in H3 Lys 4 methylation at ELC was not reversed even at late time points, thus persisting after RNApolII release.

Overall, H3 Lys 4 methylation showed a rather static behavior, consistent with its proposed role as a stable epigenetic mark of active chromatin domains. It is possible, however, that recruitment of H3 Lys 4 HMTases to a few genes (such as $E L C$ ) may occur concurrently with activation and contribute to transcriptional induction.

\section{H3 Lys 9 methylation along the ELC/SLC locus}

Differentiation-specific patterns of histone modifications are maintained over extended chromatin domains. The average size of the fragments used in our ChIP assays $(1 \mathrm{~kb})$ allowed us to analyze how H3 Lys 9 methylation extends to the chromosomal regions surrounding the promoters under investigation. The ELC gene is located on the short arm of chromosome $9(9 \mathrm{p} 13)$ in a head to tail orientation with respect to the gene encoding the related chemokine SLC (secondary lymphoid-tissue chemokine; Fig. 3), which has a low level constitutive activity in DCs (data not shown). H3 Lys 9 methylation is detectable over several kilobases, both upstream of and downstream from the ELC coding region (Fig. 3, left panel, regions D,E,F). LPS-induced demethylation and remethylation were also detected in the regions surrounding ELC. The level of H3 Lys 9 methylation dropped significantly at the intergenic regions $\mathrm{C}$ and B. Further upstream, the $S L C$ promoter A did not show any methylation at $\mathrm{H} 3 \mathrm{Lys} 9$, consistent with a low transcriptional activity. Considering that the region $\mathrm{E}$ (ELC promoter) lies more than $4 \mathrm{kbp}$ from both regions $\mathrm{D}$ and $\mathrm{F}$, that the size of the fragments in the starting extracts is around 1 $\mathrm{kbp}$, and that the density of H3 Lys 9 methylation at the $E L C$ gene is low as compared to heterochromatic genes (Fig. 2d), we can conclude that, presumably, a few nucleosomes scattered along the gene and upstream of it are methylated at Lys 9. This pattern also suggests that H3 Lys 9 methylation may contribute to the tight and independent regulation of a specific gene with respect to

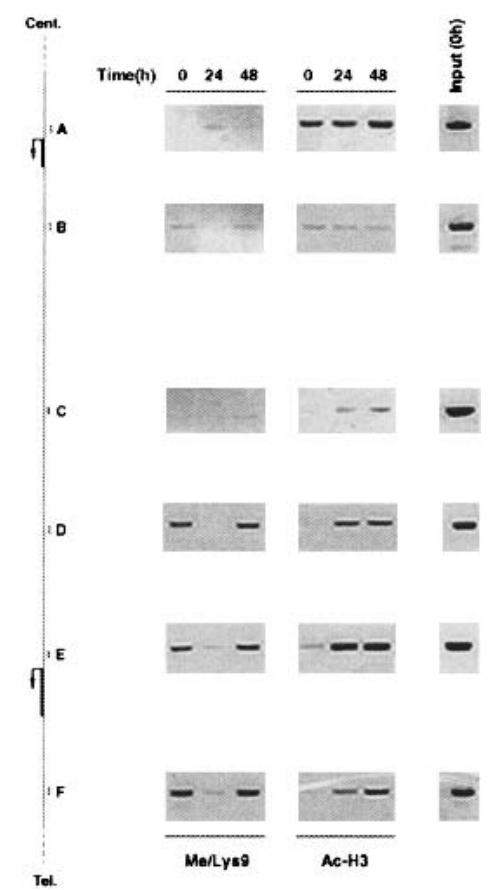

Figure 3. Histone $\mathrm{H} 3$ methylation at Lys 9 across the ELC/SLC locus. Sequence data were retrieved from the National Center for Biotechnology Information (NCBI; accession no. 17451799). (Left) A schematic representation of the region containing the SLC and ELC genes. Cent., centromere; Tel., telomere. Positions of the sets of primers (A-F) used are shown. (Middle) ChIP assays carried out with an anti-methyl H3 Lys 9 antibody. In the right panels, anti-acetyl H3 ChIP assays show the levels of $\mathrm{H} 3$ acetylation over the same region. Input: PCR products obtained with each set of primers using as template a fraction of the ChIP inputs (untreated samples). In DCs from this donor a complete remethylation of the ELC gene and surrounding regions was observed at $48 \mathrm{~h}$ after LPS stimulation. The distances between the regions amplified are $\mathrm{A}>\mathrm{B} 3.6 \mathrm{Kbp} ; \mathrm{B}>\mathrm{C} 6.5$ $\mathrm{Kbp}$; C > D $4.5 \mathrm{Kbp}$; D > E 4.2 Kbp; E > F 4.6 Kbp.

adjacent transcription units, thus preventing any kind of potential transcriptional interference.

\section{Conclusions}

Our results indicate that H3 Lys 9 methylation at inducible genes accounts for a fraction of euchromatic H3 Lys 9 methylation, is dynamically regulated, and is probably used to generate a time window in which gene activity must be confined. One interesting possibility is that $\mathrm{H} 3$ Lys 9 methylation may prevent early induction of a gene, which may occur due to the activation of the required transcription factors at a time before the gene should be transcribed. Thus, H3 Lys 9 methylation and demethylation add an additional regulatory layer to inducible gene expression.

Several mechanistic issues remain to be answered, particularly those regarding the reversal of H3 Lys 9 methylation. Hypothetic mechanisms include demethylation by histone-demethylases, cleavage of methylated tails, and replacement/degradation of methylated histone $\mathrm{H} 3$ (Jenuwein and Allis 2001). The possible existence of histone demethylases acting at specific euchromatic regions (possibly by transcription factor-mediated recruitment), without affecting the stable H3 Lys 9 mark at the level of heterochromatin, is particularly intriguing. 
However, although a histone demethylase activity was described 30 years ago (Paik and Kim 1973), no protein with such an activity has been reported to date. The recent hypothesis that a potential catalytic domain in Elp3-related histone acetyltransferases may have the requisites to carry out histone demethylation reactions is of extreme interest and awaits experimental verification (Chinenov 2002). If the methyl group is removed from H3 Lys 9 through a demethylation reaction, then an obvious possibility is that $\mathrm{H} 3$ Lys 9 methylation at the level of strategically positioned nucleosomes interferes with transcription at least in part by preventing acetylation of the same residue. An alternative mechanism for relieving repression mediated by methylated $\mathrm{H} 3$ Lys 9 may be represented by the selective transfer or mobilization of the methylated octamers exerted by chromatin remodelling complexes recognizing this modification. In this regard, it should be noticed that the first of the two chromodomains of CHD1 and CHD2, two members of the CHD (Chromodomain/吕elicase/ㅁNA-binding) family of SNF2-related helicases, have the essential structural features required for $\mathrm{H} 3$ Lys 9 binding (Jacobs and Khorasanizadeh 2002; Nielsen et al. 2002), thus suggesting that they may dock to, and mobilize, nucleosomes methylated at $\mathrm{H} 3$ Lys 9.

The behavior of H3 Lys 9 methylation in the experimental system we investigated (Fig. 4) suggests that it may contribute to both basal and post-induction repression of tightly regulated inducible genes. However, this is not a universal mechanism regulating inducible gene expression, because a number of inducible genes tested appeared not to be associated with H3 Lys 9 methylation. The genes we found to be methylated at H3 Lys 9 have slower kinetics of activation than non-methylated ones. For instance, RNAPolII recruitment to the $I k B \alpha$, $M I P-1 \alpha$, and $I L-8$ genes is already maximal at $1-2 \mathrm{~h}$ after stimulation, while it peaks between 4 and $8 \mathrm{~h}$ at the $I L-12 p 40$ gene, at $24 \mathrm{~h}$ at the ELC gene and between 24 and $48 \mathrm{~h}$ at the $M D C$ gene. This suggests that the mechanism for H3 Lys 9 removal may be intrinsically inefficient or slow. We therefore envisage the possibility that H3 Lys 9 methylation may be exploited as a repressive mark only at the level of inducible genes with relatively slow kinetics of activation.

\section{Materials and methods}

\section{Antibodies}

Modification-specific antibodies recognizing modified histones were from Upstate Biotechnology Inc, (UBI; Lake Placid, NY). The antibody

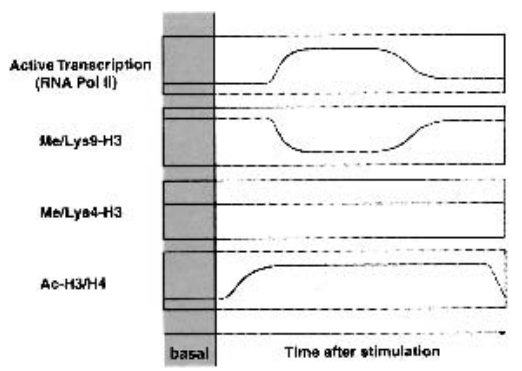

Figure 4. A schematic representation of histone methylation and acetylation changes occurring at a subset of inducible genes. RNApolII recruitment and release kinetics are shown in parallel to histone acetylation and methylation changes occurring at a subset of inducible inflammatory genes. against RNApolII large subunit rbpI was from Santa Cruz biotechnology (sc-899).

\section{DC preparation}

Monocytes were purified by positively sorting peripheral blood mononuclear cells using anti-CD14 conjugated magnetic microbeads (Miltenyi Biotec, Bergisch Gladbach, Germany). DCs were generated by culturing monocytes for $5 \mathrm{~d}$ in RPMI-10\% endotoxin-free FCS (Hyclone) supple-

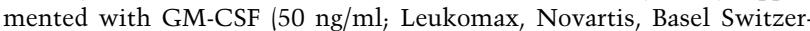
land) and IL-4 (1000 U/ml).

Chromatin Immunoprecipitation Assay (ChIP)

ChIP was carried out as previously described (Saccani et al. 2002). Sequences of promoter-specific primers and a detailed experimental protocol are available upon request.

\section{Acknowledgments}

We are grateful to Antonio Lanzavecchia and Marcus Thelen for critically reading the manuscript. This work was partially supported by the Swiss National Science Foundation (grant no. 31-66720.01 to GN).

The publication costs of this article were defrayed in part by payment of page charges. This article must therefore be hereby marked "advertisement" in accordance with 18 USC section 1734 solely to indicate this fact.

\section{References}

Bannister, A.J., Zegerman, P., Partridge, J.F., Miska, E.A., Thomas, J.O., Allshire, R.C., and Kouzarides, T. 2001. Selective recognition of methylated lysine 9 on histone $\mathrm{H} 3$ by the HP1 chromo domain. $\mathrm{Na}$ ture 410: 120-124.

Berger, S.L. 2001. An embarrassment of niches: The many covalent modifications of histones in transcriptional regulation. Oncogene 20: 3007-3013.

Boggs, B.A., Cheung, P., Heard, E., Spector, D.L., Chinault, A.C., and Allis, C.D. 2002. Differentially methylated forms of histone $\mathrm{H} 3$ show unique association patterns with inactive human $\mathrm{X}$ chromosomes. Nat. Genet. 30: 73-76.

Briggs, S.D., Bryk, M., Strahl, B.D., Cheung, W.L., Davie, J.K., Dent, S.Y., Winston, F., and Allis, C.D. 2001. Histone H3 lysine 4 methylation is mediated by Set 1 and required for cell growth and rDNA silencing in Saccharomyces cerevisiae. Genes \& Dev. 15: 3286-3295.

Chinenov, Y. 2002. A second catalytic domain in the Elp3 histone acetyltransferases: A candidate for histone demethylase activity? Trends Biochem. Sci. 27: 115-117.

Heard, E., Rougeulle, C., Arnaud, D., Avner, P., Allis, CD., and Spector, D.L. 2001. Methylation of histone H3 at Lys-9 is an early mark on the $\mathrm{X}$ chromosome during $\mathrm{X}$ inactivation. Cell 107: 727-738.

Hwang, K.K., Eissenberg, J.C., and Worman, H.J. 2001. Transcriptional repression of euchromatic genes by Drosophila heterochromatin protein 1 and histone modifiers. Proc. Natl. Acad. Sci. 98: 11423-11427.

Jacobs, S.A. and Khorasanizadeh, S. 2002. Structure of HP1 chromodomain bound to a lysine 9-methylated histone H3 tail. Science 295: 2080-2083

James, T.C., Eissenberg, J.C., Craig, C., Dietrich, V., Hobson, A., and Elgin, S.C. 1989. Distribution patterns of HP1, a heterochromatinassociated nonhistone chromosomal protein of Drosophila. Eur. J. Cell Biol. 50: 170-180.

Jenuwein, T. 2001. Re-SET-ting heterochromatin by histone methyltransferases. Trends Cell Biol. 11: 266-273.

Jenuwein, T. and Allis, C.D. 2001. Translating the histone code. Science 293: $1074-1080$

Karsunky, H., Zeng, H., Schmidt, T., Zevnik, B., Kluge, R., Schmid, K.W Duhrsen, U., and Moroy, T. 2002. Inflammatory reactions and severe neutropenia in mice lacking the transcriptional repressor Gfil. Nat. Genet. 30: 295-300.

Lachner, M., O'Carroll, D., Rea, S., Mechtler, K., and Jenuwein, T. 2001 Methylation of histone $\mathrm{H} 3$ lysine 9 creates a binding site for HP1 proteins. Nature 410: 116-120.

Lehming, N., Le Saux, A., Schuller, J., and Ptashne, M. 1998. Chromatin components as part of a putative transcriptional repressing complex. Proc. Nat1. Acad. Sci. 95: 7322-7326. 
Litt, M.D., Simpson, M., Gaszner, M., Allis, C.D., and Felsenfeld, G. 2001. Correlation between histone lysine methylation and developmental changes at the chicken beta-globin locus. Science 293: 24532455.

Ma, H., Baumann, C.T., Li, H., Strahl, B.D., Rice, R., Jelinek, M.A., Aswad, D.W., Allis, C.D., Hager, G.L., and Stallcup, M.R. 2001. Hormone-dependent, CARM1-directed, arginine-specific methylation of histone H3 on a steroid-regulated promoter. Curr. Biol. 11: 19811985.

Minc, E., Courvalin, J.C., and Buendia, B. 2000. HP1 $\gamma$ associates with euchromatin and heterochromatin in mammalian nuclei and chromosomes. Cytogenet. Cell. Genet. 90: 279-284.

Nagy, P.L., Griesenbeck, J., Kornberg, R.D., and Cleary, M.L. 2002. A trithorax-group complex purified from Saccharomyces cerevisiae is required for methylation of histone H3. Proc. Nat1. Acad. Sci. 99: 9094.

Nakayama, J., Rice, J.C., Strahl, B.D., Allis, C.D., and Grewal, S.I. 2001. Role of histone H3 lysine 9 methylation in epigenetic control of heterochromatin assembly. Science 292: 110-113.

Nielsen, A.L., Ortiz, J.A., You, J., Oulad-Abdelghani, M., Khechumian, R., Gansmuller, A., Chambon, P., and Losson, R. 1999. Interaction with members of the heterochromatin protein 1 (HP1) family and histone deacetylation are differentially involved in transcriptional silencing by members of the TIF1 family. EMBO J. 18: 6385-6395.

Nielsen, S.J., Schneider, R., Bauer, U.M., Bannister, A.J., Morrison, A., O'Carroll, D., Firestein, R., Cleary, M., Jenuwein, T., Herrera, R.E., et al. 2001. $\mathrm{Rb}$ targets histone $\mathrm{H} 3$ methylation and $\mathrm{HP} 1$ to promoters. Nature 412: 561-565.

Nielsen, P.R., Nietlispach, D., Mott, H.R., Callaghan, J., Bannister, A., Kouzarides, T., Murzin, A.G., Murzina, N.V., and Laue, E.D. 2002. Structure of the HP1 chromodomain bound to histone H3 methylated at lysine 9. Nature 416: 103-107.

Nishioka, K., Chuikov, S., Sarma, K., Erdjument-Bromage, H., Allis, C.D., Tempst, P., and Reinberg, D. 2002. Set9, a novel histone H3 methyltransferase that facilitates transcription by precluding histone tail modifications required for heterochromatin formation. Genes \& Dev. 16: 479-489.

Noma, K., Allis, C.D., and Grewal, S.I. 2001. Transitions in distinct histone $\mathrm{H} 3$ methylation patterns at the heterochromatin domain boundaries. Science 293: 1150-1155.

Ogawa, H., Ishiguro, K., Gaubatz, S., Livingston, D.M., and Nakatani, Y. 2002. A complex with chromatin modifiers that occupies E2F- and Myc-responsive genes in G0 cells. Science 296: 1132-1136.

Paik, W.K. and Kim, S. 1973. Enzymatic demethylation of calf thymus histones. Biochem. Biophys. Res. Commun. 51: 781-788.

Peters, A.H., Mermoud, J.E., O'Carroll, D., Pagani, M., Schweizer, D., Brockdorff, N., and Jenuwein, T. 2002. Histone H3 lysine 9 methylation is an epigenetic imprint of facultative heterochromatin. Nat. Genet. 30: 77-80.

Peters, A.H., O'Carroll, D., Scherthan, H., Mechtler, K., Sauer, S., Schofer, C., Weipoltshammer, K., Pagani, M., Lachner, M., Kohlmaier, A., et al. 2001. Loss of the Suv39h histone methyltransferases impairs mammalian heterochromatin and genome stability. Cell 107: 323-337.

Rea, S., Eisenhaber, F., O'Carroll, D., Strahl, B.D., Sun, Z.W., Schmid, M., Opravil, S., Mechtler, K., Ponting, C.P., Allis, C.D., et al. 2000. Regulation of chromatin structure by site-specific histone H3 methyltransferases. Nature 406: 593-599.

Ryan, R.F., Schultz, D.C., Ayyanathan, K., Singh, P.B., Friedman, J.R., Fredericks, W.J., and Rauscher, 3rd, F.J. 1999. KAP-1 corepressor protein interacts and colocalizes with heterochromatic and euchromatic HP1 proteins: A potential role for Kruppel-associated box-zinc finger proteins in heterochromatin-mediated gene silencing. Mol. Cell. Biol. 19: 4366-4378

Saccani, S., Pantano, S., and Natoli, G. 2002. p38-Dependent marking of inflammatory genes for increased NF-kappa B recruitment. Nat. Immunol. 3: 69-75.

Sallusto, F. and Lanzavecchia, A. 1994. Efficient presentation of soluble antigen by cultured human dendritic cells is maintained by granulocyte/macrophage colony-stimulating factor plus interleukin 4 and downregulated by tumor necrosis factor alpha. J. Exp. Med. 179: 1109-1118.

Schultz, D.C., Ayyanathan, K., Negorev, D., Maul, G.G., and Rauscher, 3rdr, F.J. 2002. SETDB1: A novel KAP-1-associated histone H3, lysine 9-specific methyltransferase that contributes to HP1-mediated silencing of euchromatic genes by KRAB zinc-finger proteins. Genes \& Dev. 16: 919-932.

Seeler, J.S., Marchio, A., Sitterlin, D., Transy, C., and Dejean, A. 1998 Interaction of SP100 with HP1 proteins: A link between the promyelocytic leukemia-associated nuclear bodies and the chromatin compartment. Proc. Natl. Acad. Sci. 95: 7316-7321.

Strahl, B.D., Ohba, R., Cook, R.G., and Allis, C.D. 1999. Methylation of histone $\mathrm{H} 3$ at lysine 4 is highly conserved and correlates with transcriptionally active nuclei in Tetrahymena. Proc. Natl. Acad. Sci. 96: 14967-14972.

Strahl, B.D. and Allis, C.D. 2000. The language of covalent histone modifications. Nature 403: 41-45.

Toney, L.M., Cattoretti, G., Graf, J.A., Merghoub, T., Pandolfi, P.P., Dalla-Favera, R., Ye, B.H., and Dent, A.L. 2000. BCL-6 regulates chemokine gene transcription in macrophages. Nat. Immunol. 1:214220.

Wang, H., Cao, R., Xia, L., Erdjument-Bromage, H., Borchers, C., Tempst, P., and Zhang, Y. 2001. Purification and functional characterization of a histone H3-lysine 4-specific methyltransferase. Mol. Cell 8: $1207-1217$.

Zhang, Y. and Reinberg, D. 2001. Transcription regulation by histone methylation: Interplay between different covalent modifications of the core histone tails. Genes \& Dev. 15: 2343-2360. 


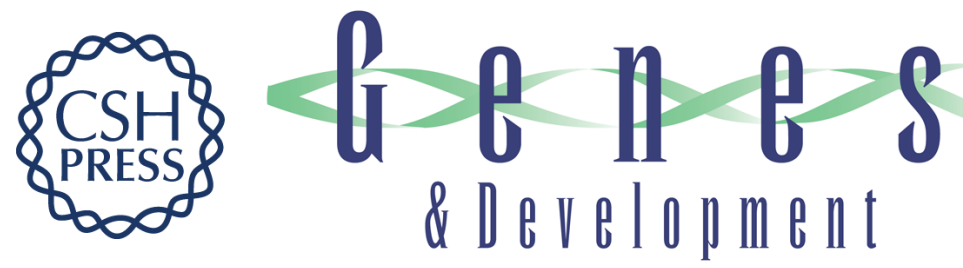

\section{Dynamic changes in histone H3 Lys 9 methylation occurring at tightly regulated inducible inflammatory genes}

Simona Saccani and Gioacchino Natoli

Genes Dev. 2002, 16:

Access the most recent version at doi:10.1101/gad.232502

\section{References This article cites 39 articles, 18 of which can be accessed free at: http://genesdev.cshlp.org/content/16/17/2219.full.html\#ref-list-1 \\ License}
Email Alerting corner of the article or click here. Service

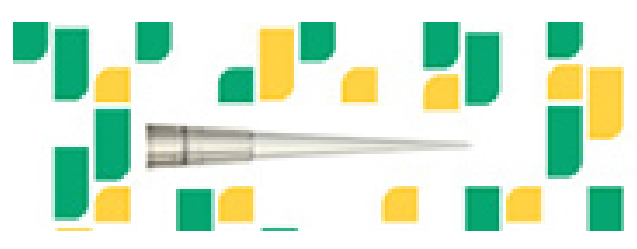

